\title{
Research on the collaborative construction and sharing of educational information resources
}

\author{
Feng-juan Liu \\ School of Educational Sciences, Shaanxi University of Technology, Hanzhong, China
}

\begin{abstract}
To resolve problems with schools wasting resources building similar repositories or databases of educational resources, this paper proposes a design and operational model of collaborative construction and sharing of educational information resources. This model proposes regional databases to be initiated by the government, developed by business corporations and used by the schools. This model should prove to guide the development of educational information resources in a commercialized, orderly mode of development to improve the quality of educational resources, increase the repository of content for a region and avoid the problem of redundancy and repetition in building such repositories.
\end{abstract}

Keywords: Educational information resources; Regional collaborative construction and sharing; Educational technology; Equal educational opportunities

\section{Introduction}

Education information resource refers to the digital education and teaching resources within the information environment, which including digital teaching cases, e-books, multimedia software and so on, It is the inevitable product of information technology being applied in teaching education. It becomes the indispensable teaching resources in the information age, and more and more students and teachers are concerned on it. All schools spontaneously began to build a school-based educational information resource library. Educational authorities have begun to allocate special funds to enrich the construction of digital educational information resources to meet the needs of teachers and students. Admittedly, the massive school constructing educational resources of schools at all levels is the result of digital education educators attaching great importance to the information resources. School constructing educational resources enriched the network of educational information resources, made the students and teachers with the application of digital information resources to carry out awareness education and learning, and experienced the true meaning of digital learning[1].

However, the digital education information resource base is still under construction early and at the exploratory stage, which has not yet formed a unified educational information resource library construction mode. The special construction funds are allocated by the education authorities in the area directly to each school. And schools decide by themselves how to proceed educational information resource library construction. School constructing educational resources is seemingly flourishing, but there is a big problem and deficiencies. Firstly, the construction of special funds dispersed information resources, resources are not rich and can not form the scale. Then, the various schools order the same resources direct order, so the duplication is inevitable[2]. The next, teachers are free to develop their own non-commercial software which are not high quality.

\section{The basis of constructions}

(1) The own characteristics of resources determine the construction and sharing.

Educational information resource has the following features: the extensiveness of knowledge, the convenience of retrieval, the share of Internet, the 
interactivity and value added feature in the communication process. These features determines the educational information resources can be achieved " area to build in a network environment sharing. " For example, highly shared characteristics of educational information resources determines the flow of information in the case permit, an educational information resources can achieve "one to many " online synchronization application within the region and affect each other. Therefore, using the traditional paper-based media repository built school age school libraries established idea to build the information age educational information resource library, is the main cause of the current low level redundant construction[3].

(2) Information resources construction and sharing.can greatly improve the economic efficiency.

The substance of educational resources construction and sharing is completely negate the existing. The development and application of school constructing educational resources are replaced by regional education department through administrative control measures, centralized controlling the special education relations funds, coordinating the relationship among development, operation and application of educational information resources. Under the premise of not increasing funding to maximize the development of high-quality resources, resulting in greater efficiency in the application .

(3) Regional constructions and sharing is the inevitable trend of development and application of information resources.

In the past 30 years, information technology develops rapidly, the computer, networking and modern communications technology are rapidly changing the ways of people living, communication. In the information age, knowledge of geometry incremental, urgent human needs anytime, anywhere manner across time and space constraints, timely, accurate and comprehensive capture, processing, storage, and create information. Human activity has shifted from substance dependence to information dependency, the information regarded as the most important resource has been focused by human. Digital education information resources can be many applications, and can be applied in different places. These characteristics determine the educational information resource "area sharing " may become a model to develop applications, and is the inevitable trend of digital educational resources in the development and application of information: information technology in all walks of life change today, we are destined to revolutionize education teaching structure. The digital education information resources offsite storage, access, ubiquitous applications will bear the brunt. At the same time, educational information resources, " Regional Sharing " in the development and application mode to reduce regional differences in the allocation of educational resources, there are other modes irreplaceable advantages[4].

\section{The development and application mode of information resources regional constructions and sharing}

The development and application of educational resources regional constructions and sharing is a systematic project involving educational information resource development, application and management.

(1) The main organization and implementation.

Because the vast majority of schools are public schools, so the education department is the main organization and implementation which is in charge of regional information resource regional constructions and sharing. Firstly, the education department is responsible for the development of this regional center of educational information resource library construction plans, annual information resources to identify and allocate special construction funding for education. Secondly, according to user needs, the educational software development company or a qualified internal school educational software development company is commissioned to carry out the commercial development of education information resources. Thirdly, the regional education department constructs the digital educational information repository which is the open source type and builds high-speed interconnection network operating platform 
between the repository and all school districts.

(2) Commercial development of quality education information resources.

The sources of educational information resources in the development and application mode of regional constructions and sharing is no longer developing teachers' own educational software freely. It is replaced by the high quality commercial software developed by educational software company which are commissioned by the education authorities. Firstly, educational software developers with its strong economic strength and experience in software development take the ways of business operations to develop educational information resources, whose product quality can be on par with the market selling game software. Then, educational software developers in the development of relevant educational information resources, should be targeted at any time consultant hired teaching, pedagogy and psychology consultants, to ensure that educational information resource in the game, entertaining and interactive basis, not missing the educational, scientific and artistic.

(3) Educational information resource user groups within the region.

Educational information resource user groups within the region mainly refers to the school teachers, students and parents. Educational resources constructions and sharing mode can solve two issues : education information resource business development model, can greatly improve the quality of educational software. The special construction fund is focused to set up regional centers for educational information repository that can greatly enrich educational information resource limits. The ultimate goal of educational resources regional constructions and sharing is to greatly limit the regional center for educational information resource library, so that teachers, students and parents within the jurisdiction of the user base can enjoy everything they need within the high quality education information resources.

\section{The operation mechanism of the proposed mode}

About educational resources regional constructions and sharing mechanism to develop applications to run mode, we get some borrowed from " Chinese Journal Full-text Database " mode of operation. We believe that education information resource regional constructions and sharing is mainly to coordinate the relationship between resource providers, resource libraries and resources between user groups, summarized as "government-led, business development, school-application” .

(1) The regional education department is in charge of leading the formation of regional educational information resource library center and resources network platform.

According to the development trend of China 's national conditions and educational information technology equipment, and as a department under the Ministry of Education regional museum or two units of audio-visual education center education technology and equipment can assume direct the work: to build regional centers of educational information resource library of software and hardware platforms science education information resource planning multi-dimensional classification of resources at any time convenient to expand, update and remote users to retrieve.

(2) Regional education department introduces appropriate competition to order high quality education information resources.

There are two channels for commercial software developers actively involved in the construction of educational information resource areas: One is the bidding competition, the software developers with strong strength are commissioned to tailor the proper educational information resources, which has the feature of one-time purchasing and a permanent using for the end user. Another is the agreement related to resource exploitation regional center for education information resource center and commercial software developers, such as the payment of educational information resource development costs to the end user hits or downloads and other means. 


\section{Conclusions}

Digital educational resources information resources is unlike paper-based media, digital education information resources construction model "school building a database" thought suited the network environment. It is a new problem we currently facing is how to realize the regional digital education information resource sharing. With the rapid development of information technology, "government-led , business development, school application" digital education information resource area proposed sharing issue, the technical obstacles have been or will be fully resolved, its economic benefits, advantages of resource quality, resource storage capacity , and other aspects of the shared channel is obvious. We believe that in the near future, sharing a regional center of educational information resource library will become the mainstream of educational information resources construction.

\section{Acknowledgements}

This research is supported by 2014 Annual Research of Shaanxi Province Education Science "Twelfth Five-Year Plan" :Research on the mechanism for regional university-local building and sharing digital teaching resources in cloud era (NO.SGH140733) and 2013

Annual Youth Research of National Education Information Technology Research "Twelfth Five-Year Plan" : Research of the regional school balanced development under the background of educational informatization (NO.136241481)

\section{References}

[1] Farideh Hamidi, Maryam Meshkat, Maryam Rezaee, Mehdi Jafari, "Information technology in education", Procedia Computer Science, pp. 369-373, 2011.

[2] Charles R. McClure, "Promoting education for information resources management in the federal government", Government Information Quarterly, pp. 1-11, 1995.

[3] Jef Peeraer, Peter Van Petegem, "Integration or transformation: Looking in the future of Information and Communication Technology in education in Vietnam", Evaluation and Program Planning, pp. 47-56, 2015.

[4] Charles N. Nzivo, Chen Chuanfu, "International Students' Perception of Library Services and Information Resources in Chinese Academic Libraries", The Journal of Academic Librarianship, pp. 129-137, 2013. 